\title{
Long-term Results of Palliative Stereotactic Radiotherapy of Barcelona Clinic Liver Cancer Stage C Hepatitis B-Related Hepatocellular Carcinoma
}

\author{
CKK Choi, CHM Ho, MYP Wong, RWK Leung, FCS Wong, SY Tung, FAS Lee \\ Department of Clinical Oncology, Tuen Mun Hospital, Hong Kong
}

\begin{abstract}
Objective: To assess the long-term effectiveness of palliative stereotactic body radiotherapy (SBRT) in patients with large unresectable Barcelona Clinic Liver Cancer stage C hepatitis B-related hepatocellular carcinomas (HCCs). Methods: Consecutive HCC cases treated with fractionated SBRT between January 2008 and December 2010 were analysed. The long-term survival and response rate were evaluated. Univariate and multivariate analyses were performed to identify the significant predictors of survival.

Results: In total, 32 cases were analysed, with median gross tumour volume was $509.5 \mathrm{~cm}^{3}$ (range, 2.2-3088 $\left.\mathrm{cm}^{3}\right)$. Median treatment prescription was $32 \mathrm{~Gy}$ (range, 20-40 Gy) in five to 10 fractions over 1 to 2 weeks. Median followup was 13.4 months; median survival was 13.3 months $(95 \%$ confidence interval [CI]=11.4-15.2). Stable and partial tumour response rates by RECIST criteria were $69 \%$ and $31 \%$, respectively. Alpha-fetoprotein reduction at $\geq 3$ months after radiotherapy $(p=0.018)$ and gain in body weight after SBRT $(p<0.001)$ were significantly associated with longer survival after multivariate analysis.

Conclusion: SBRT with dose individualisation can be delivered safely to large unresectable tumours in patients with $H B V$-related HCC. The median survival after SBRT in this study was 13.3 months. Alpha-fetoprotein reduction at $\geq 3$ months and weight gain after radiotherapy were positive prognostic factors for longer survival. More prospective studies are warranted to confirm these results.
\end{abstract}

Key Words: Carcinoma, hepatocellular; Hepatitis B, Radiosurgery

Correspondence: Dr CKK Choi, Department of Clinical Oncology, Tuen Mun Hospital, Hong Kong

Email: calvinkkchoi@hkbh.org.hk

Submitted: 17 Jul 2020; Accepted: 8 Mar 2021

Contributors: All authors designed the study, acquired the data, analysed the data, drafted the manuscript, and critically revised the manuscript for important intellectual content. All authors had full access to the data, contributed to the study, approved the final version for publication, and take responsibility for its accuracy and integrity.

Conflicts of Interest: The authors declare no conflict of interest.

Funding/Support: This research received no specific grant from any funding agency in the public, commercial, or not-for-profit sectors.

Ethics Approval: This study was approved by New Territories West Cluster Research Ethics Committee (Ref NTWC/REC/20040). Informed consent was obtained from patients for stereotactic body radiotherapy.

Acknowledgements: The authors acknowledge Mr Jia-Jie Huang for his statistical analysis support. 


\title{
中文摘要
}

\section{巴塞隆拿肝癌分期系統第3期乙型肝炎相關肝細胞癌患者的紓緩性立體 定位放射治療的長期結果}

\author{
蔡國強、何凱文、黃然柏、梁永堅、黃志成、董瑨、李安誠 \\ 目的：評估紓緩性立體定位放射治療（SBRT）對巨大無法切除的巴塞隆拿肝癌分期系統第3期乙型 \\ 肝炎相關肝細胞癌 ( HCC) 患者的長期療效。 \\ 方法 : 分析2008年1月至2010年12月期間接受SBRT分次治療的HCC患者。評估長期存活率和腫瘤緩 \\ 解率, 並以單變量和多變量分析檢視存活期的重要預測因子。 \\ 結果：分析SBRT分次治療的HCC患者共32例, 中位腫瘤體積 $509.5 \mathrm{~cm}^{3}$ (介乎2.2-3088 $\mathrm{cm}^{3}$ ) 。處方劑 \\ 量中位數為32 Gy (20-40 Gy ) /5-10 frs/1-2週。中位隨訪期為13.4個月, 中位存活期為13.3個月（95\% \\ 置信區間：11.4至15.2個月）。根據固體腫瘤反應評估標準（RECIST），腫瘤大小無變化和部分緩 \\ 解分別為 $69 \%$ 和 $31 \%$ 。多變量分析顯示患者放療3個月或之後的甲胎蛋白減少 $(\mathrm{p}=0.018)$ 和SBRT後 \\ 體重增加 $(\mathrm{p}<0.001)$ 與較長存活期顯著相關。 \\ 結論 : 對於與乙型肝炎病毒相關的不可切除HCC患者, 劑量個體化SBRT是安全的療法。這項研究顯 \\ 示患者在SBRT後中位存活期為13.3個月。放療後3個月或以上的甲胎蛋白下降, 以及放療後體重增加 \\ 是延長存活期的正向預後因素。需要進行更多前瞻性研究證實以上結果
}

\section{INTRODUCTION}

Hepatocellular carcinoma (HCC) is the fifth most common cancer in Hong Kong and sixth most common cancer worldwide. Eighty-nine percent of HCC cases are hepatitis B virus (HBV)-related. There were more than 1834 new cases in 2017. It was the third most common cause of cancer deaths in males in $2017 .{ }^{1}$

In the past, radiotherapy (RT) was seldom used in the management of HCC because of the high risk of liver toxicity. Recent studies have shown that stereotactic body radiotherapy (SBRT) in HCC has high control rates with low liver toxicities. ${ }^{2}$ The Barcelona Clinic Liver Cancer staging system (BCLC) does not include radiotherapy as a treatment option. According to the BCLC treatment algorithm, stage $\mathrm{C}$ locally advanced HCC is treated with sorafenib. ${ }^{3}$ With the advances in radiotherapy planning and delivery, ${ }^{4}$ SBRT has been shown to be a safe and effective treatment for unresectable HCC. ${ }^{5-7}$ The National Comprehensive Cancer Network Guidelines for HCC recommends RT as a locoregional therapy option. ${ }^{8}$

To the best of our knowledge, there is limited literature evaluating the role of SBRT in BCLC stage C HBVrelated HCC. In our previous paper, ${ }^{7}$ we reported radiotherapy details, short-term response, safety, and toxicity of palliative SBRT in 36 patients with HBVrelated HCC. In the present study, we investigated the long-term efficacy of palliative SBRT for HBV-related $\mathrm{HCC}$, as well as prognostic factors.

\section{METHODS}

\section{Patients}

The data of consecutive patients with HBV-related BCLC stage C HCC, Child's grade A to B8 without distant metastases treated with SBRT from 2008 to 2010 were retrieved retrospectively from hospital records in 2015. Eligibility criteria are described in our previous paper studying the impact of SBRT on liver function, with stages other than BCLC stage C excluded?

\section{Radiotherapy Treatment}

Patients were prescribed $4 \mathrm{~Gy}$ per fraction to the planning target volume for five to 10 fractions. $^{7}$

\section{Statistical Analysis}

The data were analysed using SPSS (Windows version 23.0; IBM Corp., Armonk [NY], United States). KaplanMeier testing was used for univariate overall survival (OS) analysis with $\mathrm{p}<0.05$ considered significant. Cox regression was used for those variables that were significant in the univariate OS analysis. 


\section{RESULTS}

\section{Cases}

Between January 2008 and December 2010, 32 consecutive patients with BCLC stage $\mathrm{C}$ unresectable HCC underwent SBRT at our institution (Table 1).

Table 1. Patient characteristics. *

\begin{tabular}{|c|c|}
\hline & No. (\%) \\
\hline \multicolumn{2}{|l|}{ Sex } \\
\hline Male & 27 (84.4\%) \\
\hline Female & $5(15.6 \%)$ \\
\hline Age, y, median (range) & $58.5(36-90)$ \\
\hline \multicolumn{2}{|c|}{ Karnofsky Performance status } \\
\hline 100 & $2(6.3 \%)$ \\
\hline $80-90$ & $23(71.9 \%)$ \\
\hline $60-70$ & $7(21.9 \%)$ \\
\hline \multicolumn{2}{|l|}{ Pre-radiotherapy status } \\
\hline HBeAg positive & $7(21.9 \%)$ \\
\hline \multicolumn{2}{|c|}{ Pre-radiotherapy Child-Pugh class } \\
\hline A & 30 (93.8\%) \\
\hline $\mathrm{B}$ & $2(6.3 \%)$ \\
\hline \multicolumn{2}{|c|}{ Post-radiotherapy Child-Pugh class } \\
\hline A & 27 (84.4\%) \\
\hline$B$ & $3(9.4 \%)$ \\
\hline C & $2(6.3 \%)$ \\
\hline \multicolumn{2}{|c|}{ Pre-radiotherapy HBV DNA level ${ }^{\dagger}$} \\
\hline Negative & $12(37.5 \%)$ \\
\hline Positive & $20(62.5 \%)$ \\
\hline \multicolumn{2}{|c|}{ Post-radiotherapy HBV DNA level } \\
\hline Negative & 22 (68.8\%) \\
\hline Positive & $10(31.3 \%)$ \\
\hline \multicolumn{2}{|c|}{ Invasion of portal vein or bile duct } \\
\hline Yes & $11(34.4 \%)$ \\
\hline No & $21(65.6 \%)$ \\
\hline \multicolumn{2}{|l|}{ Size of tumour } \\
\hline$\leq 5 \mathrm{~cm}$ & $9(28.1 \%)$ \\
\hline$>5-10 \mathrm{~cm}$ & $8(25.0 \%)$ \\
\hline$>10-15 \mathrm{~cm}$ & $10(31.3 \%)$ \\
\hline$>15 \mathrm{~cm}$ & $5(15.6 \%)$ \\
\hline \multicolumn{2}{|l|}{ BCLC } \\
\hline Stage C & $32(100 \%)$ \\
\hline \multicolumn{2}{|l|}{ Previous treatment } \\
\hline \multicolumn{2}{|c|}{ Previous hepatic resection/RFA } \\
\hline Yes & $8(25.0 \%)$ \\
\hline No & $24(75.0 \%)$ \\
\hline Sorafenib before RT & $6(18.8 \%)$ \\
\hline Sorafenib after RT & $5(15.6 \%)$ \\
\hline TACE & $23(71.9 \%)$ \\
\hline Steroids & 0 \\
\hline Baseline RUQ pain & $4(12.5 \%)$ \\
\hline \multicolumn{2}{|l|}{ Baseline AFP ( $n=31), \mu g / L$} \\
\hline$<20$ & $7(22.6 \%)$ \\
\hline$\geq 20$ & $24(77.4 \%)$ \\
\hline
\end{tabular}

Abbreviations: AFP = alpha-fetoprotein; $B C L C=$ Barcelona Clinic Liver Cancer staging system; $\mathrm{HBeAg}=$ hepatitis B virus e antigen; $\mathrm{HBV}=$ hepatitis $\mathrm{B}$ virus; RFA = radiofrequency ablation; $\mathrm{RT}=$ Radiotherapy; $\mathrm{R} \cup \mathrm{Q}=$ right upper quadrant; $\mathrm{TACE}$ = transarterial chemoembolisation.

* Data are shown as No. (\%) of patients, unless otherwise specified.

+ HBV DNA level definition: negative $<1.0 \times 10^{5}$ copies $/ \mathrm{mL}$; positive $>1.0 \times 10^{5}$ copies $/ \mathrm{mL}$.
These patients had large unresectable tumours, with median gross tumour volume (GTV) $509.5 \mathrm{~cm}^{3}$ (range, 2.2-3088 $\mathrm{cm}^{3}$ ). The tumour size was $>10 \mathrm{~cm}$ in $15(46.9 \%)$ patients and $>15 \mathrm{~cm}$ in five $(15.6 \%)$ patients. The median age was 58.5 years (range, 36-90 years). The majority (25 [78.1\%]) of patients had a Karnofsky Performance status $\geq 80$. In 2015, 30 patients were dead. Of the surviving two patients, one patient was alive for 5.9 years since treatment and censored on 12 October 2015 when data were collected. The other patient was lost to follow-up and censored on 26 March 2010, 1.5 years after treatment.

\section{Treatment}

All 32 patients received 4 Gy per fraction with a median total prescription dose of $32 \mathrm{~Gy}$ (range, 20-40 Gy). Prior treatments included surgical resection or radiofrequency ablation in eight $(25 \%)$ patients, and transarterial chemoembolisation (TACE) in $23(71.9 \%)$ patients. Sorafenib was administered to six (18.8\%) patients before SBRT and five (15.6\%) patients after SBRT. No patient received steroid therapy. Details of the radiotherapy can be found in our previous study. ${ }^{?}$

\section{Symptom Control \\ Pain}

The most common presenting symptoms were right upper quadrant pain and distension. After 3 to 4 weeks of radiotherapy, up to $90 \%$ of patients had significant pain relief.

\section{Body Weight}

Weight loss was defined as a decrease in body weight of $\geq 10 \%$ within the 3 months before treatment. In total, $12(37.5 \%)$ of the 32 cases had increased body weight 1 month after radiotherapy; univariate and multivariate analysis showed that this was significantly associated with longer survival $(\mathrm{p}<0.001$ and $\mathrm{p}<0.001)$ [Tables 2 and 3]. In all, 11 (34.4\%) patients had unchanged body weight after radiotherapy and nine $(28.1 \%)$ patients experienced weight loss. Univariate and multivariate analysis showed that patients with weight loss were observed to have shorter survival $(\mathrm{p}<0.001$ and $\mathrm{p}<0.001$ ) [Tables 2 and 3].

\section{Changes in Alpha-Fetoprotein after Radiotherapy}

Only 31 patients were evaluated for change of alphafetoprotein (AFP) levels after radiotherapy because of missing data for one patient. In total, 24 of 31 patients (77.4\%) had elevated AFP level ( $>20 \mu \mathrm{g} / \mathrm{L})$ at the time 
Table 2. Univariate analysis of variables associated with overall survival.

\begin{tabular}{lc}
\hline Variable & p Value \\
\hline Age & 0.89 \\
Sex & 0.12 \\
Karnofsky Performance status & 0.32 \\
Child-Pugh class before radiotherapy & 0.81 \\
Change in Child-Pugh class & 0.02 \\
Invasion of portal vein or bile duct, or portal vein & 0.86 \\
thrombosis & \\
AJCC staging & 0.24 \\
Size of liver tumour & 0.09 \\
Chemotherapy before radiotherapy & 0.30 \\
Chemotherapy after radiotherapy & 0.74 \\
TACE & 0.60 \\
Pain at presentation & $<0.001$ \\
Change in body weight & $<0.001$ \\
Change in AFP & 0.041 \\
\hline
\end{tabular}

Abbreviations: AFP $=$ alpha-fetoprotein; AJCC $=$ American Joint Committee on Cancer; TACE = transarterial chemoembolisation

Table 3. Multivariate analysis of variables associated with overall survival.

\begin{tabular}{lr}
\hline Variable & $\mathrm{p}$ Value \\
\hline Change in Child-Pugh class & 0.693 \\
Pain at presentation & 0.205 \\
Change in body weight & \\
$\quad$ Decrease & $<0.001$ \\
$\quad$ No change & 0.594 \\
Alpha-fetoprotein group & \\
$\quad$ Decrease for $\geq 3$ months after radiotherapy & 0.018 \\
Increase after radiotherapy & 0.879 \\
\hline
\end{tabular}

of treatment planning. Seven $(22.6 \%)$ patients had reduction of AFP level that persisted for $\geq 3$ months after radiotherapy. Seven (22.6\%) patients had increased AFP level after radiotherapy, and 17 patients had decreased or static AFP level within 3 months after radiotherapy. In the seven patients with reduction of AFP level, median survival was 640 days (range, 398-2190 days). Univariate and multivariate analysis showed that reduced AFP level was significantly associated with longer survival $(p=0.041$ and $p=0.018)$ [Tables 2 and 3]. In the seven patients with increased AFP levels after radiotherapy, median survival was 210 days (range, 101-1277 days).

\section{Response and Survival}

The median survival of all 32 patients was 13.3 months (95\% confidence interval $[\mathrm{CI}]=11.4-15.2$ ) The 1 -year and 3-year survival was $62.5 \%$ (95\% CI=53.9\%-71.1\%) and $14.1 \% \quad(95 \% \quad \mathrm{CI}=7.74 \%-20.5 \%)$, respectively.
Figure 1 shows the Kaplan-Meier curves illustrating factors affecting the OS. Figure 2 shows Kaplan-Meier curves illustrating OS of patients with HCC after SBRT.

\section{DISCUSSION}

In Hong Kong, HBV-related HCC is clinically different to hepatitis C-related HCC in Western populations. It is relatively larger in size and some of the tumours are encapsulated. In terms of efficacy, we previously demonstrated the response to and efficacy of moderate doses of hypofractionated SBRT for patients with unresectable HCC. ${ }^{7}$ Most patients had significant pain relief after radiotherapy. In the present study, we investigated the long-term efficacy of palliative SBRT for HBV-related HCC.

With a median follow-up of 13.4 months, no patients developed progressive disease within 3 months after radiotherapy. The tumour response rate by mRECIST criteria was $69 \%$. The median survival was 13.3 months. Que et $\mathrm{al}^{5}$ published the treatment results of SBRT in patients with BCLC stage C HCC. Their series found the overall RECIST response rate was $81.5 \%$ (complete response, $36.2 \%$; partial response, $45.3 \%$ ), with a stable disease rate of $14.4 \%$. Their median dose was $40 \mathrm{~Gy}$ in three to five fractions (range, 39-40 Gy). In the current study, the tumour size was much larger and the equivalent doses delivered in 2-Gy fractions (EQD2) Gy10 were lower than those in Que et al's study (37.3 Gy10 vs $60 \mathrm{~Gy} 10)^{5}$ [Table 4]. Thus, the higher response rate in Que et al's study may have been due to the smaller size of tumours as well as the higher radiation dose..$^{5}$

The 1-year OS was $62.5 \%$, and 3-year OS was $14.1 \%$. The 1-year and 3-year OS rates in Que et al's series were $56 \%$ and $28 \%$, respectively. ${ }^{5}$ The survival rates are comparable. Que et al's response rate was much higher than that in our study. ${ }^{5}$ Again, it may be due to the tumour size, which was much smaller than that in our study cases, or higher radiation dose. In univariate analysis, the present study showed that change in Child-Pugh class, pain at presentation, change in body weight, and change in AFP were significantly related to OS. TACE before RT was not significant but there was a trend to improve OS. In multivariate analysis, only change in body weight and decrease in AFP were significantly associated with OS.

This is the first study to show that patients with large unresectable HCCs can benefit from a small palliative 

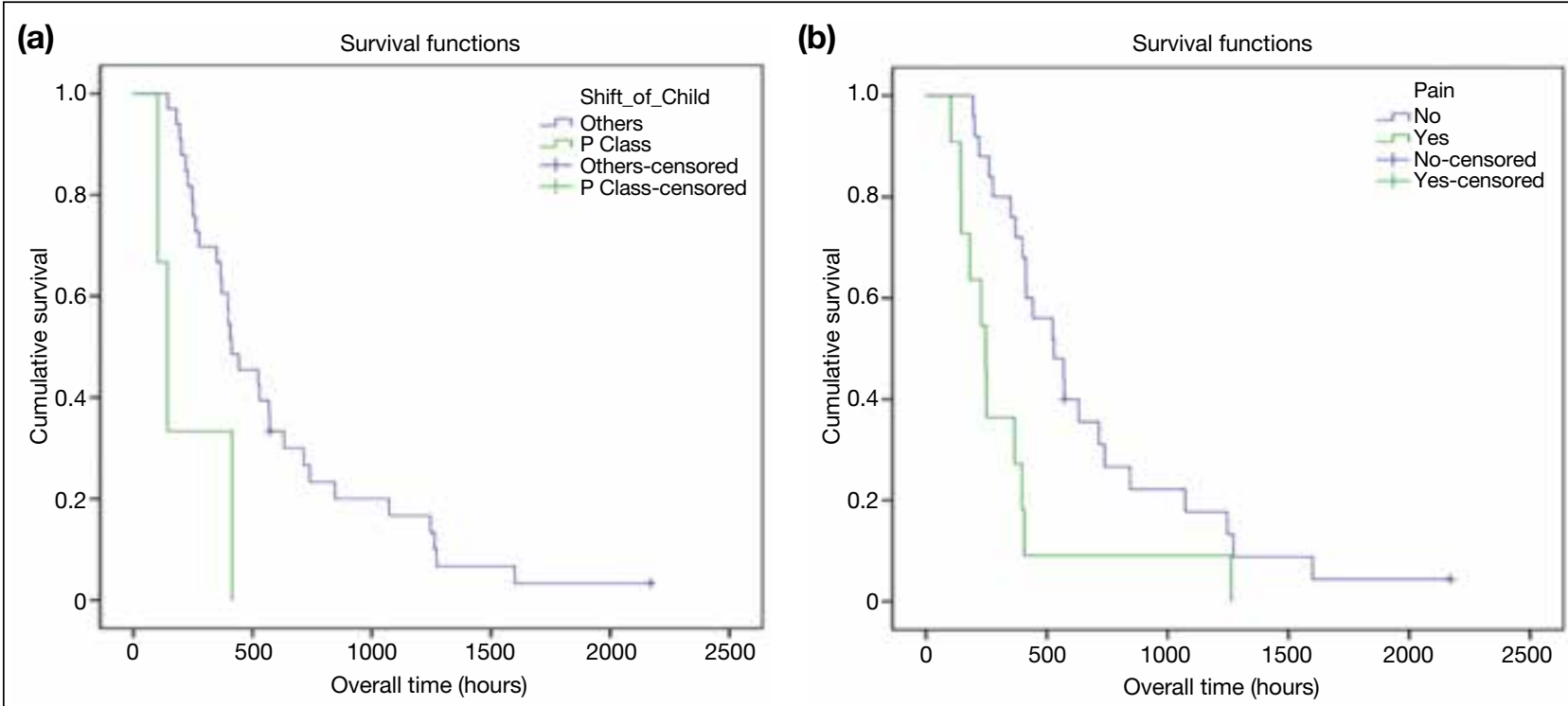

(c)

(d)

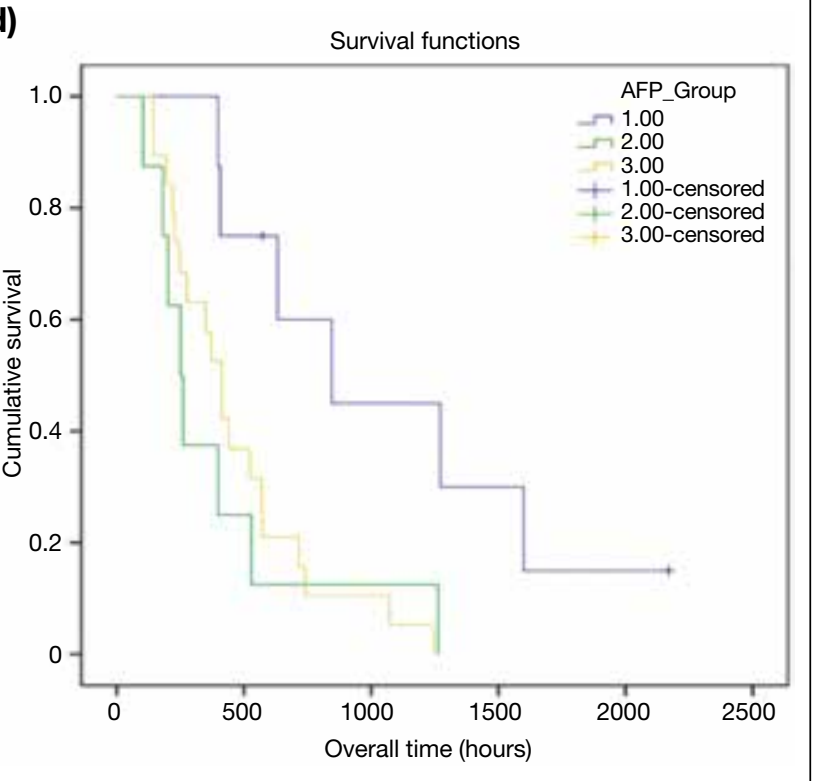

Figure 1. Kaplan-Meier curves illustrate the overall survival of hepatocellular carcinoma: (a) with (green curve) or without (blue curve) change in Child-Pugh class; (b) with (green curve) or without (blue curve) persistent pain after radiotherapy; (c) decrease (blue curve), no change (green curve), or increase (yellow curve) in body weight (BW); and (d) alpha-fetoprotein (AFP) level decreased $>3$ months after radiotherapy (blue curve), decreased $<3$ months after radiotherapy or remained static (yellow curve), or increased after radiotherapy (green curve).

dose. We found a significant survival benefit. It is worthwhile to administer palliative radiotherapy to large HBV-related liver tumours. An individualised dose prescription is safe up to a ceiling dose of $40 \mathrm{~Gy}$ in 10 fractions in accordance with dose constraints to uninvolved liver (V30 <40\% and mean dose $<28 \mathrm{~Gy}$ ) and uninvolved liver volume $>700 \mathrm{~cm}^{3}$ in a relatively large liver tumour (median GTV $509.5 \mathrm{~cm}^{3}$; range 2.2$3088 \mathrm{~cm}^{3}$ ).

\section{CONCLUSION}

Palliative SBRT with individualised dose up to $40 \mathrm{~Gy}$ in 10 fractions can be delivered safely to large unresectable HBV-related HCCs. The median survival rate of patients with BCLC stage C HCC in this study was 13.3 months. AFP reduction at $\geq 3$ months and body weight gain after radiotherapy were positive prognostic factors. More prospective studies are warranted to confirm these results. 


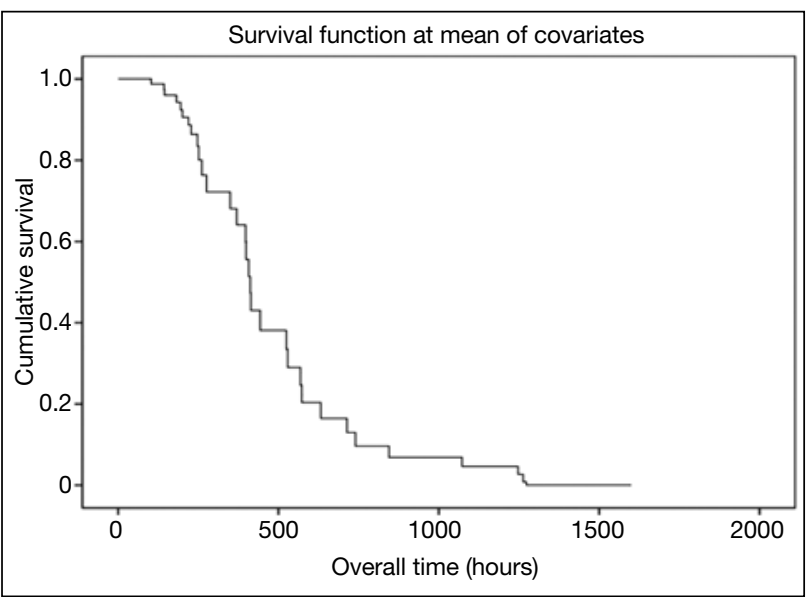

Figure 2. Kaplan-Meier curve illustrating the overall survival of hepatocellular carcinoma after stereotactic body radiotherapy.
Table 4. Efficacy of stereotactic body radiotherapy in patients with Barcelona Clinic Liver Cancer stage $\mathrm{C}$ hepatocellular carcinoma.

\begin{tabular}{lcc}
\hline & Present study & Que et al $^{5}$ \\
\hline No. of patients & 32 & 139 \\
RILD, No. (\%) & 0 & $9(6 \%)$ \\
Change in Child-Pugh & 3 (9\%) [1 from A to B; & Not available \\
class, No. (\%) & 1 from A to C; & \\
& 1 from B to C] & \\
Fractions & $5-10$ & $3-5$ \\
Total dose range, Gy & $20-40$ & $26-40$ \\
EQD2 Gy10 & 37.3 & 60 \\
Tumour $>10$ cm & $47 \%$ & $19.9 \%$ \\
Response rate & & \\
$\quad$ Complete response & $0 \%$ & $36.2 \%$ \\
$\quad$ Partial response & $31 \%$ & $45.3 \%$ \\
$\quad$ Static disease & $69 \%$ & $14.4 \%$ \\
Median survival, mo & 13.3 & 15.4 \\
$\quad$ 1-year survival & $62.5 \%$ & $56 \%$ \\
3-year survival & $14.1 \%$ & $28 \%$ \\
\hline
\end{tabular}

Abbreviations: EQD2 = equivalent doses delivered in 2-Gy fractions; $\mathrm{RILD}=$ radiation-induced liver disease.

C hepatocellular carcinoma: Results of a single-institutional experience on stereotactic body radiation therapy. Medicine (Baltimore). 2020;99:e21561.

6. Chopra S, George K, Engineer R, Rajamanickam K, Nojin S, Joshi $\mathrm{K}$, et al. Stereotactic body radio therapy for inoperable large hepatocellular cancers: results from a clinical audit. Br J Radiol. 2019;92:20181053.

7. Choi CK, Lee FA, Lam TC, Wong FC, Wong VY, Lui C, et al. Impact of fractionated stereotactic body radiotherapy on liver function in patients with hepatitis B virus-related hepatocellular carcinoma: clinical and dosimetric analysis. Hong Kong J Radiol. 2013;16:94-9.

8. Wahl DR, Stenmark MH, Tao Y, Pollom EL, Caoili EM, Lawrence TS, et al. Outcomes after stereotactic body radiotherapy or radiofrequency ablation for HCC. J Clin Oncol. 2016;34:452-9. 